\title{
Medication adherence issues in patients treated for COPD
}

\author{
Ruben D Restrepo \\ Melissa T Alvarez \\ Leonard D Wittnebel \\ Helen Sorenson \\ Richard Wettstein \\ David L Vines \\ Jennifer Sikkema-Ortiz \\ Donna D Gardner \\ Robert L Wilkins
}

Department of Respiratory Care, The University of Texas Health Science

Center at San Antonio, Texas, USA
Correspondence: Ruben D Restrepo MD, RRT, FAARC

Department of Respiratory Care, The University of Texas Health Science Center at San Antonio, Texas. MSC 6248. San Antonio TX 78229, USA

$\mathrm{Tel}+\mathrm{I} 2105678858$

Fax + I 2105678852

Email restrepor@uthscsa.edu

\begin{abstract}
Although medical treatment of COPD has advanced, nonadherence to medication regimens poses a significant barrier to optimal management. Underuse, overuse, and improper use continue to be the most common causes of poor adherence to therapy. An average of $40 \%-60 \%$ of patients with COPD adheres to the prescribed regimen and only 1 out of 10 patients with a metered dose inhaler performs all essential steps correctly. Adherence to therapy is multifactorial and involves both the patient and the primary care provider. The effect of patient instruction on inhaler adherence and rescue medication utilization in patients with COPD does not seem to parallel the good results reported in patients with asthma. While use of a combined inhaler may facilitate adherence to medications and improve efficacy, pharmacoeconomic factors may influence patient's selection of both the device and the regimen. Patient's health beliefs, experiences, and behaviors play a significant role in adherence to pharmacological therapy. This manuscript reviews important aspects associated with medication adherence in patients with COPD and identifies some predictors of poor adherence.
\end{abstract}

Keywords: adherence, chronic obstructive pulmonary disease, compliance, inhalers, inhalation technique, patient preference, quality of life

\section{Introduction to management issues in COPD}

According to the World Health Organization (WHO) estimates, currently 210 million people have COPD and 3 million people died of COPD in 2005. The WHO predicts that COPD will become the fourth leading cause of death worldwide by 2030 (COPD 2007). The burden of COPD assessed by disability-adjusted life years (DALYs) ranks 10th worldwide (WHO 2008). Total deaths from COPD are projected to increase by more than $30 \%$ in the next 10 years unless urgent preventive measures are in place (COPD 2007).

Although COPD cannot be cured, optimal management provides symptom control, slows progression of the disease, and may improve the quality of life (Kaplan and Ries 2005; Rodriguez-Roisin 2005). Management of COPD becomes suboptimal when physicians fail to prescribe appropriate therapies, due to poor adherence to evidencebased guidelines and underdiagnosis (Snider 1985; Foster et al 2007), or when patients fail to adhere to prescribed treatment regimens. There are a limited number of studies on the physician knowledge and practice patterns for individuals with COPD that may result in suboptimal management and adversely affect patient outcomes (Ramsey 2000; George et al 2005; Foster et al 2007; Sestini et al 2007).

Adherence is defined as "the extent to which a person's behavior (in terms of taking medications, following diets, or executing lifestyle changes) coincides with medical or health advice" (Haynes et al 1979). Adherence to medication regimens is often suboptimal when patients are on long-term pharmacotherapy using repeat prescriptions. A study published by the WHO estimated $50 \%$ adherence or less for patients on long-term pharmacotherapy (WHO 2003). 
Adhering to inhaled medications is of paramount importance in the management of patients with COPD in both clinical and ambulatory settings. These pharmacologic agents include bronchodilators and corticosteroids used in a variety of aerosol devices that include small volume nebulizers (SVNs), pressurized metered-dose inhalers (pMDIs), and dry powder inhalers (DPIs). Selection of the medication and the device typically depends on the efficacy of the different inhaled medications and the devices. However, this selection is often limited by the availability of a match between the medication prescribed and the aerosol device. While it is desirable that the medications prescribed to a patient are delivered through the same or similar devices, adherence to the right medication - device combination may be influenced by commercial availability. The medication - device availability problem will be compounded by the phasing-out of CFC-propelled pMDIs at the end of 2009 as proposed by the Federal register ruling (FDA 2007). Replacement of CFCpropelled pMDIs by hydrofluoroalkane (HFA)-propelled pMDIs has been more difficult than expected since it has resulted in a redesign of the entire pMDI metering-valve system at a higher cost than simply replacing the propellant. This transitioning will initially restrict the list of available agents and could have considerable financial implications in the routine management of patients with COPD (Rau 2005; Smyth 2005).

Medication regimens for patients with COPD are particularly vulnerable to adherence problems because of the chronic nature of the disease, the use of multiple medications or polypharmacy, and the periods of symptom remission. Patients with COPD are often prescribed aerosolized medications to use from 2 to 6 times daily plus concurrent therapy for other comorbidities that may include diabetes, hypertension, and coronary artery disease (Krigsman et al 2007a; Steinman et al 2006).

Despite the efforts of the global initiative for chronic obstructive lung disease (GOLD) to provide clinicians with the best therapeutic guidance, adherence to pharmacologic therapy among patients with COPD has been historically poor (Windsor et al 1980; Kaplan et al 1990; Dolce et al 1991; George et al 2005; Krigsman et al 2007b, c). Patients with COPD display significantly lower adherence to treatment than asthmatic patients (James et al 1985; Cochrane 1992; Haupt et al 2008). Several studies have reported that an average of $60 \%$ of patients with COPD do not adhere to prescribed therapy (Chryssidis et al 1981; Taylor et al 1984; Dompeling et al 1992; Bosley et al 1994; Krigsman et al 2007b, c; Haupt et al 2008) and that up to $85 \%$ of patients use their inhaler ineffectively (Crompton 1990; Thompson et al 1994; Van Beerendonk et al 1998; van der Palen et al 1995, 1998; Hesselink et al 2001; Serra-Batlles et al 2002). British and Swedish studies indicate that $10 \%-20 \%$ of repeat prescriptions never reach a pharmacy (Rashid 1982; Nilsson et al 1995).

Adherence to therapy in COPD is complex. Patients with COPD require adequate education on the disease process, comorbidities, and also on the use of different medications and devices (Chryssidis et al 1981; Dolce et al 1991). They often need to make important behavioral and lifestyle changes such as starting a smoking cessation program, adhering to an exercise program, and wearing oxygen.

Several methods are used to measure adherence: refill adherence based on pharmacy records of dispensed prescription or manual recording of collected prescriptions, and self-reports of compliance using medication adherence report scales (MARS) (George et al 2005). Although adherence should ideally be measured upon ingestion or administration of the medication, this is not practical for large groups. Most studies rely on a mixture of refill adherence and self-report. Since the most commonly used method to measure is the self-report (Farmer 1999) this review focuses only on this technique.

Numerous factors predispose patients with COPD to poor adherence. Recognition of the type of nonadherence in patients with COPD must be the first step in this complicated process of improving adherence. Prescription of an inhaled medication requires knowledge of different groups of medications and the potential clinical efficacy of combinations. It also requires being familiar with several aerosol delivery devices. Newer medications and devices improve clinical outcomes and ease of use but typically mean a higher out-of-pocket expense for patients. Patient's perceptions of their illness, their understanding of the treatment, and their relationship with the primary care provider are critical to adherence to therapy. It is the aim of this manuscript is to review some of these important aspects affecting adherence to medication and to identify some predictors of poor adherence in patients with COPD.

\section{Underuse, overuse, and improper use}

There are three classic types of nonadherence to therapy: underuse, overuse, and improper use. Underuse is defined as a reduction of the apparent daily use versus a standard dose of a medication that is indicated for the treatment or prevention of a disease or condition (Lipton et al 1992; 
Harrow et al 1997). Improper use or inappropriate use is confirmed by determining whether a drug is ineffective, not indicated, or if there is unnecessary duplication of therapy (Steinman et al 2006).

Although these three factors have been well defined in the literature, there is limited evidence that links specific factors to each form of nonadherence in patients with COPD. The most common type of nonadherence in patients with COPD is underuse (Harrow et al 1997; George et al 2005). By contrast, improper use is the most frequent type of nonadherence in patients older than 65 years with polypharmacy (taking 2 or more medications) (Steinman et al 2006). Factors with tendency for association with unnecessary drug use include white race, income $<\mathrm{US} \$ 30,000 /$ year, more than $6.8( \pm 2)$ of prescription medications, and lack of patient's health belief (Rossi et al 2007). In older adults, higher levels of independence and self-reliance have been associated with lower adherence to a medication regimen (Insel et al 2006). The two most common reasons for a medication to be considered inappropriate are lack of effectiveness and lack of indication (Hajjar et al 2005; Steinman et al 2006; Rossi et al 2007). Inhaled medications are not on the top 5 medications that are inappropriately used in patients older than 65 years (Hajjar et al 2005; Rossi et al 2007).

In patients with COPD, underuse is followed in frequency by overuse and improper use of the medication delivering device. Underuse could be sporadic or systematic. From forgetting an occasional dose to changing dosing schedule, patients with underuse are at a higher risk for adherencerelated morbidity. A recent evaluation of the use of ICS in primary care patients revealed that up to $30 \%$ of the patients did not have a clear indication for this medication (Lucas et al 2008). Although improper use and underuse often coexist in the same patient, improper use may not correlate with underuse (Steinman et al 2006).

There is evidence of overuse of short-acting beta agonists in patients with asthma (Lynd et al 2002), but little is known about the real incidence of overuse in patients with COPD. During respiratory distress, approximately half of the patients report using more than the prescribed amount of medications (Dolce et al 1991; Bosley et al 1994).

\section{Clinical efficacy of major classes of medications and combinations}

Determination of clinical efficacy involves evaluation of outcomes such as lung function, rate of exacerbations, and mortality. However, these outcome parameters need to be a reflection of the clinical efficacy perceived by the patient. A combination of objective and subjective clinical efficacy is a critical determinant of adherence to therapy. Inhaled corticosteroids (ICS), long-acting $\beta_{2}$-agonists (LABAs), and anticholinergics have been recommended for the treatment of COPD. LABAs are recommended by GOLD (GOLD 2007) when patients continue to experience problems on short-acting bronchodilators (SABAs). The most obvious benefit of combination therapy is in terms of patient convenience that may lead to greater treatment adherence.

\section{Lung function}

Current evidence indicates that there is statistically significant difference in $\mathrm{FEV}_{1}$ and in health status measurements in favor of LABAs (Appleton et al 2006) and ICS (Yang et al 2007). Several randomized controlled trials have found that a LABA - ICS combination therapy is associated with a significant increase over the baseline $\mathrm{FEV}_{1}$ when compared with the groups receiving placebo, LABA alone, or ICS alone (Calverley et al 2007; Nannini et al 2007a). Addition of tiotropium to the LABA - ICS combination significantly improves lung function (Aaron et al 2007). The combination of ipratropium bromide and albuterol in patients with COPD results in significant improvement in peak $\mathrm{FEV}_{1}$ compared with albuterol or ipratropium alone (Gross et al 1998). Tashkin et al (2007) reported no significant difference in lung function measured by $\mathrm{FEV}_{1}$ in a group of patients with COPD randomized to SVN, pMDI, and concomitant treatment involving SVN (morning and night) plus pMDI (afternoon and evening) using a combination of albuterol and ipratropium bromide.

\section{Rate of exacerbations, hospitalizations, and mortality}

Using LABA - ICS is associated with a significant reduction in the rate of exacerbation, admission rates, and mortality (Aaron et al 2007; Calverley et al 2007; Nannini et al 2007b, $7 \mathrm{c})$. Combination therapy may reduce 1 exacerbation of COPD every 2-4 years (Calverley et al 2007). Patients with COPD at any stage may perceive the lower health resource utilization as a motivator to adhere more rigorously to medications. However, this correlation has not been determined. Trials of short-acting anticholinergic and SABA combinations have shown a significant reduction in exacerbations compared with monotherapy, but no difference in mortality (Sin et al 2003). 


\section{Use of rescue medication}

The use of rescue medications during COPD exacerbations may seem to be the most feasible explanation for overuse. During an exacerbation, an average of 1 additional puff during the day and half a puff during the night is seen two weeks prior and after an exacerbation regardless of COPD stage (Calverley et al 2005). However, changes in rescue medication intake poorly correlate with exacerbations (Calverley et al 2005). The use of LABA - ICS has been associated with a significant reduction in mean puffs per day of SABA (Mahler et al 2002; Hanania et al 2003), significant increases in the percentage of nights with no awakenings requiring SABA versus placebo, and a significant difference in median percentage of days without use of relief medication (Calverley et al 2003a, b; Szafranski et al 2003).

\section{Safety and tolerability of major classes of medications and combinations}

Adverse events to medications are reported by $90 \%$ of the patients with COPD (Calverley et al 2007). The presence of serious side effects negatively affects adherence. An increase in the risk of pneumonia in patients with COPD using a combination of ICS and LABA has been reported in several studies (Calverley et al 2007; Nannini et al 2007b). The most frequently reported adverse event was an exacerbation of COPD. Although there is no significant difference in the occurrence of overall reported adverse events between LABA - ICS and placebo, pneumonia, candidiasis, nasopharyngitis, hoarseness, and upper respiratory tract infections (URTI) occurred more frequently when treated with a LABA - ICS combination (Table 1) (Nannini et al 2007a).

\section{Adherence to individual medications and combinations Type of medication}

Patients with COPD have the lowest adherence to a regimen that included inhaled anticholinergic agents followed in order by the inhaled sympathomimetics, theophylline, corticosteroids, and antibiotics (Dolce et al 1991) (Figure 1).

The ability to produce quick relief of symptoms or the safety profiles could explain class differences. It has been suggested that compliance to corticosteroids should be lower than to bronchodilators, because of the lack of direct symptom-relieving effect of the corticosteroids. However,
Table I Most common adverse effects with combination therapy

\begin{tabular}{llll}
\hline $\begin{array}{l}\text { Adverse } \\
\text { effect }\end{array}$ & $\begin{array}{l}\text { Nr of } \\
\text { studies }\end{array}$ & $\begin{array}{l}\text { Nr of } \\
\text { patients }\end{array}$ & OR; 95\% Cl \\
\hline Pneumonia & 7 & 5229 & OR I.80;95\% Cl I.48-2.18 \\
Candidiasis & 6 & 1958 & OR $5.73 ; 95 \%$ Cl 3.07-10.67 \\
Hoarseness & 2 & 585 & OR $8.79 ; 95 \%$ Cl I.I I-69.62 \\
Nasopharyngitis & 2 & 3535 & OR I.28;95\% Cl I.05-I.56 \\
URTI & 5 & 4963 & OR I.23; 95\% Cl I.04-I.47
\end{tabular}

Abbreviations: $\mathrm{Cl}$, confidence interval; OR, odds ratio; URTI, upper respiratory tract infections.

patients may adhere to regimens that include oral corticosteroids and antibiotics more frequently because these medications are typically prescribed for short periods of time. Since they are prescribed to deal with acute symptoms, the patients' perception is that these medications are more urgent and necessary.

\section{Complexity of medication regimens}

It has been previously reported that overall, the average number of time-contingent and as needed (P.R.N.) medications per patient may be as high as 6.26 (range, 1-16) (Dolce et al 1991). Up to $77 \%$ of patients with COPD may receive 2 or more oral-contingent medications (Dolce et al 1991). One-third typically receive 2 or more inhaled time-contingent medications, $45 \%$ receive 1 inhaled time-contingent medication, and $23 \%$ receive no inhaled time-contingent medications (Dolce et al 1991). The average of prescribed oral time-contingent and inhaled time-contingent medications are 3.53 and 1.17 , respectively. Thirty percent of patients with COPD are prescribed oral P.R.N. medications and 17\% had inhaled P.R.N. medications (Dolce et al 1991). Many of these medications have different dosing schedules. Thus, it is quite common for patients to be prescribed a combination of 5-8 oral and inhaled medications, with many medications requiring different dosing patterns.

Use of ipratropium bromide and albuterol in one inhaler is associated with a significantly lower risk of an emergency department visit or hospitalization, lower mean monthly health charges, shorter hospital stays, and greater likelihood of compliance than if used in two separate inhalers (Chrischilles et al 2002).

\section{Selection of the aerosol delivery device}

All aerosol delivery devices have relative advantages and disadvantages, as well as a potential to affect outcomes. The marketing of a myriad of aerosol delivery devices has resulted in a confusing number of choices for clinicians and 


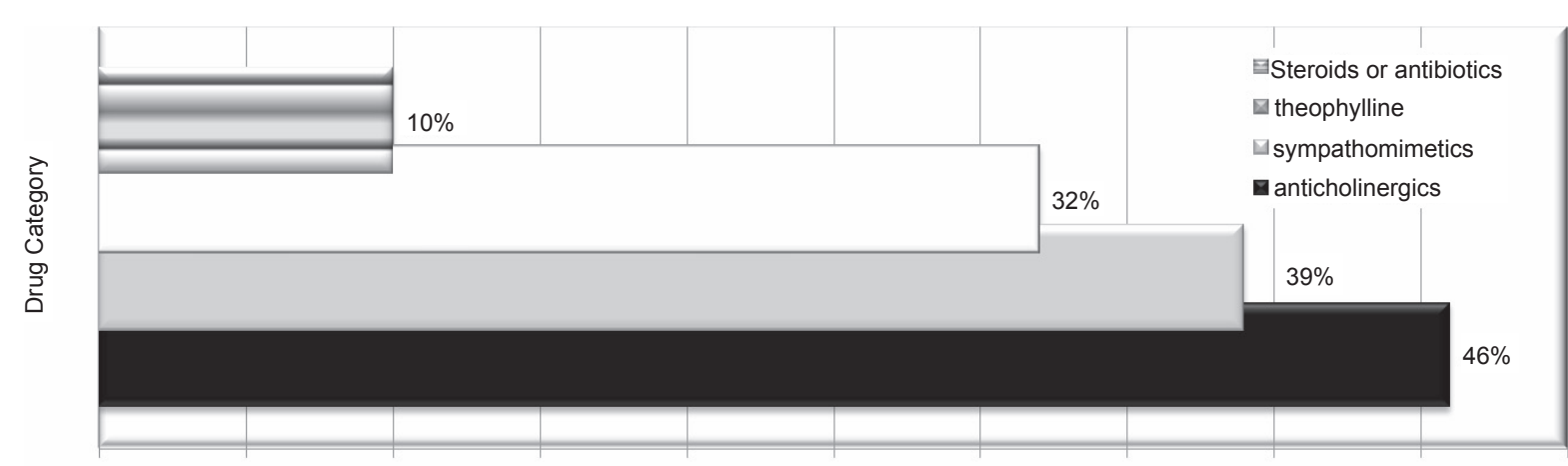

Non-adherence at least once a month

Figure I Percentage of nonadherence to prescribed medication category.

patients. Although the fundamental principle of prescribing is based on the use of the most clinical and cost-effective medication and device, choices may become influenced by factors that are not clinically relevant or evidence-based. The ability of the patient to use the prescribed device affects adherence to treatment.

\section{Clinical efficacy}

The overall conclusion of numerous studies demonstrates that there is no evidence to support clinically important differences between aerosol devices. A systematic review (Dolovich et al 2005) identified 394 randomized controlled trials (RCTs) assessing inhaled corticosteroid, $\beta_{2}$-agonist, and anticholinergic agents that were delivered by pMDI, pMDI with spacer/holding chamber, nebulizer, or DPI. None of the pooled meta-analyses found a significant difference between devices in any efficacy outcome of patients with asthma and COPD in the outpatient and hospital acute care settings. A recent clinical trial (Tashkin et al 2007) reported no appreciable changes from baseline or pair wise differences between SVN and pMDI treatment arms at weeks 6 or 12 in peak flow measurements and symptom scores of patients with COPD.

In all the pooled meta-analyses, each of the delivery devices has provided similar outcomes in patients using the correct technique for inhalation. However, clinical benefit also depends on the ability of the patients to use the device and on their adherence. Real-life observational studies that evaluated patient inhalation techniques have shown frequent improper use of pMDIs and DPIs that may result in significant clinical differences between devices.

\section{Patient acceptability and preference}

Elderly patients with COPD show a preference for the SVN with regard to effectiveness and in favor of the pMDI with regard to acceptability (Balzano et al 2000). SVN treatment is often prescribed to patients who prefer SVNs or demonstrate poor coordination with either a pMDI or DPI. Because SVNs are not as portable as pMDIs or DPIs, ambulatory patients find pMDIs and DPIs more convenient for use when they are away from home.

\section{Inhalers and dosing technique}

Although patients may adhere to the dosing schedule, they may use the inhaler improperly (McFadden 1986). Inhaler specific design features also contribute significantly to the patient's adherence to treatment (Brown et al 1992; Woodman et al 1993; van der Palen et al 1994). Patient technique is a process that encompasses an individual's previous experiences, education, abilities, and the teaching received on the specific device. These factors may interact to various degrees with the different types of inhaler devices to influence eventual technique and adherence. The typical method to evaluate inhaler technique is by assigning a score on the number of steps performed correctly out of the total number of possible steps. An evaluation of inhaler use in 316 patients suffering from asthma or COPD found that $89 \%$ of the patients made at least one mistake in the inhalation technique (van Beerendonk et al 1998). The most common skill error was "not continuing to inhale slowly after actuation of the inhaler" (69.6\%). The nonskill item most patients had difficulties with was "exhaling before the inhalation" $(65.8 \%)$. Patients who used a pMDI made significantly fewer nonskill mistakes than patients using a DPI (van Beerendonk et al 1998). A systematic review (Brocklebank and Ram 2001) using the outcome of "ideal" inhaler technique showed that the percentage of patients with all steps correct was $43 \%$ for pMDI alone, $55 \%$ for pMDI + spacer, and 59\% for DPI. There was statistical 
difference between pMDI alone and DPI or pMDI + spacer, but whether this is clinically significant is difficult to judge, particularly if cost efficacy is considered. The data support the conclusion of many reports that pMDI devices are poorly used.

When the pMDI is used, more than $50 \%$ of subjects may perform $\leq 5$ out of 9 steps correctly and only about $11 \%$ of the subjects could perform all steps correctly (Luk et al 2006) (see Table 2).

The most frequent problem is failure to coordinate actuation with inhalation and to hold their breath after inhalation. When patients are asked simple questions to establish if they have a basic understanding of their nebulized medication (eg, do you know what medications you use? how often? do you know if the medication you take has a bronchodilatory or anti-inflammatory effect?), 52\% of patients are not able to answer these questions correctly; although $91 \%$ believe that they do understand the treatment they were prescribed. Of those who are unable to answer correctly, $60 \%$ are nonadherent (Bosley et al 1996). To complicate matters, primary care physicians are not familiar with relevant features of currently available inhalers (Sestini et al 2007).

\section{Patient preference - ease of use}

In a recent comparison of the Diskus ${ }^{\circledR}$ inhaler (DK) and the Handihaler $^{\circledR}(\mathrm{HH})$ regarding preference and ease of use, although there was no difference in the number of instructions needed for both inhalers, more patients preferred the DK. The most important general items for patients were hygiene and a clear instruction leaflet (van der Palen et al 2007). Of the inhaler-specific aspects, more than $90 \%$ of patients find ease of use in general, ability to take the medication quickly, ease of use during an exacerbation, the feel in the hand, and ease of the cap important or very important (Figure 2).

Inhaler resistance is a factor that contributes to suboptimal inhalation of medication in patients with COPD. Over the

Table 2 Steps for correct use of the inhaler

\begin{tabular}{ll}
\hline Steps for correct use of the inhaler \\
\hline I. & Remove cover \\
2. & Shake inhaler well \\
3. & Hold inhaler upright \\
4. & Exhale gently \\
5. & Place mouthpiece \\
6. & Actuate canister once at the beginning of inhalation \\
7. & Inhale slowly and deeply \\
8. & Hold breath at least I0 seconds \\
9. & Breath out slowly \\
\hline
\end{tabular}

years, there has been a trend to increase inhaler resistance. Patients have a preference for devices that allow them to inhale the medication quickly (van der Palen et al 2007). Eight popular DPIs seem to be acceptable with regard to their internal resistance, but the trend to increase the resistance of inhalers may have reached a critical point with regard to acceptability (van der Palen et al 2007).

Patients report overwhelmingly (98\% vs 2\%) that perceived benefits from using a SVN over a pMDI or DPI (eg, improved breathing, greater self-confidence, and less need to contact health care providers) outweigh perceived disadvantages (eg, longer time required for nebulizer treatment and cleaning the device) (Barta et al 2002).

\section{Pharmacoeconomics}

Pharmacoeconomics has emerged to formalize the decisionmaking process for the adoption of new medications and devices. In addition, the implementation of clinical practice guidelines can be costly (Haycox and Bagust 1999). In the US, in 2000, the total annual costs related to COPD were in excess of \$US32 billion (COPD 2008). In the US, 97\% of people over 65 years who receive incomplete Medicare coverage need supplemental insurance (Roberts 2006). Since the Medicare Prescription Drug Improvement and Modernization Act of 2003 only went into effect in 2006, its impact on suboptimal medication use is still to be determined (Maio et al 2005).

\section{Medication-related cost}

Although underuse can result in morbidity and health care cost, the cost of the medication is believed to be one of the most important determinants of underuse (Hanlon et al 2001; Stuart 2004; Maio et al 2005). Tiotropium has demonstrated the highest expected net benefit for ratios of the willingness to pay per quality-adjusted life-year (QALY) (Rutten-van Mölken et al 2007). The incremental cost per additional QALY is lower with tiotropium than salmeterol or ipratropium bromide (Oba 2007). The practice of offering tiotropium bromide for patients with COPD-related hospitalizations instead of ipratropium bromide is favored (Onukwugha et al 2008). There is a potential overall cost saving of $83 \%$ after the addition of tiotropium to the medical regimen of patients with COPD (Lee et al 2006). Fluticasone - salmeterol (FLU - SAL) and budesonide - formoterol (BUD - FOR) are the most cost effective strategies. However, there is a slight superiority of FLU - SAL. Incremental cost-effectiveness of FLU - SAL versus SAL was $€ 679.5$ (US\$1,001) per avoided exacerbation and $€ 3.3$ (US\$4.86) per symptom-free day (Dal et al 2007). 


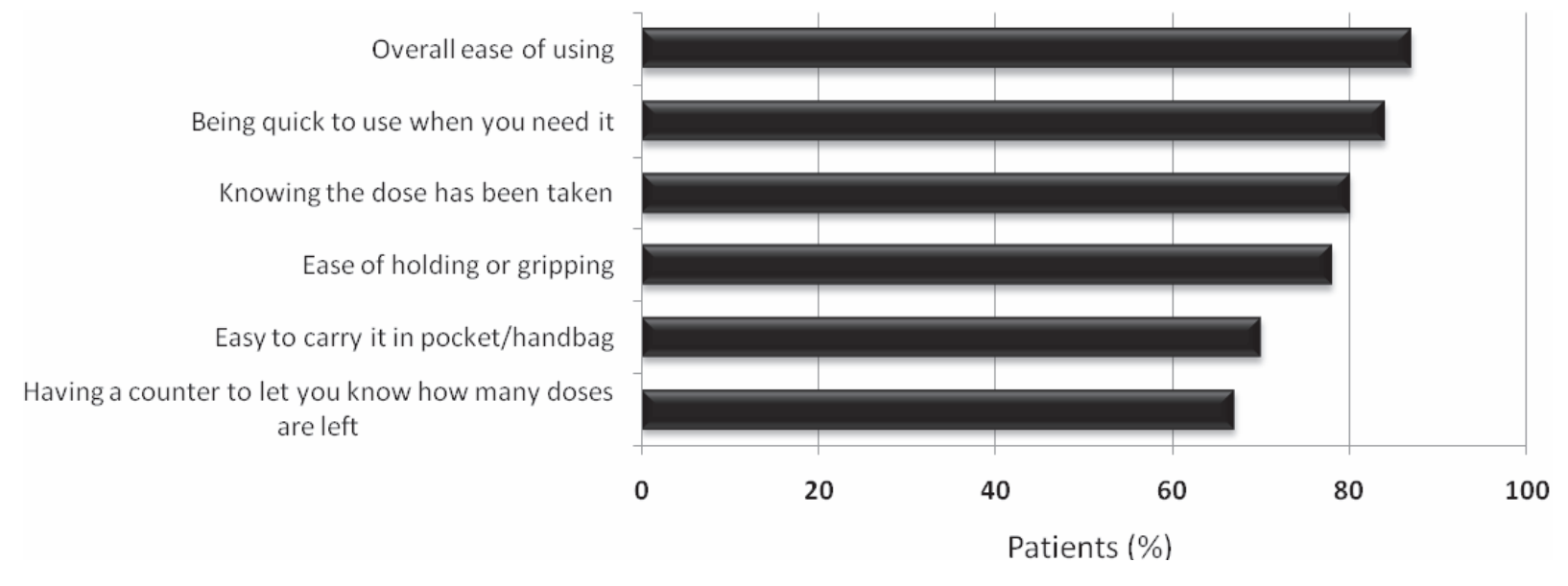

Figure 2 Features of an inhaler considered “very important" by patients with COPD (Data from Moore and Stone 2004).

\section{Device-related cost}

Important breakthroughs in biotechnology and nanotechnology have resulted in the creation of a myriad of aerosol devices that have dramatically improved medication delivery to patients with respiratory diseases (Dames et al 2007; Dhand 2008). However, these advances have come at a steep price. It is well known that the costs of both the DPIs and SVNs are substantially higher than pMDI devices for all classes of medication (Brocklebank and Ram 2001), that there is lack of many DPIs in generic forms, and that while $80 \%$ of SVNs and medications are reimbursable by Medicare, pMDIs and DPIs are not covered (Rau 2005). Although spacers significantly improve drug delivery, the high cost of these simple attachments may be sufficient to deter many patients from using them. Although routine substitution of pMDI therapy for SVN therapy can be accomplished with considerable reductions in the hospital setting (Bowton et al 1992), several authors have reported that no aerosol delivery device could be categorically rated as not cost-effective (Peters et al 2002).

\section{Patient beliefs, experiences, and behaviors}

Significant differences in health beliefs, experiences, and behaviors are observed between COPD patients with different levels of adherence. While education plays an important role on modifying beliefs, patients are likely to modify the recommended therapy based on how they feel or their level of dyspnea.

COPD patients with suboptimal adherence have insufficient understanding about their illness and the options for managing their illness, show a low level of satisfaction with and faith in the treating physician, and rely more on natural remedies (George et al 2005). They also perceive the management of COPD as a mystery and show low confidence in drug therapy (Turner et al 1995; Incalzi et al 2001; George et al 2005).

The degree of difficulty to handle some medications and patient satisfaction with the information shared by the doctors is the more significant patient experiences that correlate with adherence to therapy for COPD (George et al 2005). The level of patient satisfaction heavily depends on the adequacy of communication between clinician and patient as perceived by the patient. Although complexity of medication regimens, concerns about side effects, cost of treatment, and the number of regular medications in the regimen have been considered critical to adherence, these experiences have not been consistently correlated with poor adherence by all the studies (George et al 2005).

Since patients with COPD are often coached to increase their prescribed doses when exacerbations are identified, the behavior of decreasing the doses when feeling well explains quite well the frequency of underuse in some patients with COPD. This change in frequency of therapy creates confusion about medications and results in sometimes not taking any actions when exacerbations arrive (George et al 2005).

A recent meta-analysis (DiMatteo et al 2007) suggested that the objective severity of patients' disease conditions, and their awareness of this severity, can predict their adherence. Patients who are most severely ill with serious diseases may be at greatest risk for nonadherence to treatment. Depression further complicates therapy adherence among COPD patients. Depressed medical patients are 3 times more likely to be noncompliant with medication regimens, exercise, diet, health related behavior, vaccination, and appointments (DiMatteo et al 2007). Patients with 
chronic illness are also likely to adhere to therapy if they trust the provider who prescribes the regimen, if there is evidence that the regimen is effective and does not cause distressing or frightening side effects that outweigh any therapeutic benefits, if the regimen does not significantly interfere with important daily activities, and if it does not have a significant impact on the individual's sense of identity (Strauss and Glaser 1975).

Table 3 shows beliefs, experiences, and health behaviors identified as strong predictors of low adherence to treatment in 276 patients with COPD. Each item is listed in order of statistical significance compared with subjects with high adherence (George et al 2005).

\section{Patient satisfaction, patient preferences, and quality of life}

Although patient's view of therapy is important as discussed above, relatively little has been investigated on the patient view of therapy involving monotherapy versus combination therapy and the use of a particular aerosol device. Most investigators assess the suitability of this form of therapy on response to lung function tests, reported improvements in exercise ability, and other indices of clinical efficacy mentioned above. Evaluation of issues such as well-being and symptom control, self-confidence, dependency, time and technical issues, as well as side effects and adherence provides a global assessment of quality of life. In a survey of 82 patients with chronic lung conditions on domiciliary nebulizer therapy, $98 \%$ of the patients receiving SVNs therapy reported favoring SVNs over pMDIs due to improved breathing, greater selfconfidence, and less need to contact health care providers (Barta et al 2002).

The greatest change in quality of life have been reported when combination LABA - ICS is used in patients with COPD (mean reduction of 3.0 units over 3 years) compared with a placebo group (a mean score of 48.4 at baseline, with an increase of 0.2 unit in the placebo group) (Calverley et al 2007). The combination BUD - FOR has a more significant reduction in the St George Respiratory Questionnaire (SGRQ) than the FLU - SAL or placebo (D'Urzo et al 2001; Aaron et al 2007; Nannini et al 2007b).

Patients with COPD who are treated with an albuterol/ ipratropium combination via SVN have statistically significant improvements from baseline in the SGRQ at 6 weeks. The concomitant use of SVN plus pMDI maintains significant improvement in total questionnaire score and symptom sub-scores at week 12 (Tashkin et al 2007).
Table 3 Beliefs, experiences, and health behaviors identified predictors of low adherence to treatment in 276 patients with COPD. The highlighted variables explained almost $20 \%$ variance in nonadherence in this study (George et al 2005)

\section{Beliefs}

I do not have sufficient understanding about my illness

My doctors are not very knowledgeable

Natural remedies are safer than medicines

My doctors have limited management options to offer me

I do not have sufficient understanding about the options for managing my illness

The management of my illness is a mystery for me

\section{Experiences}

It is unpleasant to use some of my medications

It is physically difficult to handle some of my medications

I am not satisfied with the information my doctors share with me

My doctors are not compassionate

My doctors don't spend adequate time with me

\section{Behaviors}

I get confused about my medications

I vary my recommended management based on how I am feeling

I put up with my medical problems before taking any action

I make changes in the recommended management to suit my lifestyle

\section{Self-reported adherence}

Although several techniques are used to measure adherence, the most commonly used is based on self-reports, which tend to overestimate adherence (Farmer 1999). MARS is commonly used for self-reported adherence. A score of 25 indicates perfect adherence (George et al 2005).

Fifty percent of patients with COPD do not take their medications as prescribed (James et al 1985). Patients on regimens of up to 4 times daily who take less than $70 \%$ of the dose prescribed, and those on regimens of 5 times daily or over who take less than $60 \%$ of the dose prescribed, are defined as poorly adherent (Moriskey et al 1986; Bosley et al 1996). Underuse, especially during periods of respiratory distress, is more common than overuse (Chryssidis et al 1981; James et al 1985; Dolce et al 1991).

While a qualitative study of compliance to medication and lifestyle modification in patients with COPD found that all patients except one reported good adherence to medication (Jones et al 2004), the overall reported adherence to treatment in COPD ranges from $41.3 \%$ (Taylor et al 1984) to $57 \%$ (Dolce et al 1991; Bosley et al 1994). Factors such as fear of dyspnea and feelings of vulnerability appear to contribute to improvement in compliance. Ninety-three patients were asked how often they missed doses from their nebulizers and $66 \%$ 
stated that they never did ( $61 \%$ of the nonadherers and $72 \%$ of the adherers). Six percent reported missing doses only once a month, 10\% admitted to missing doses once a week, and $7 \%$ ( $11 \%$ of the nonadherers and $3 \%$ of the adherers) stated that they missed a dose once a day (Bosley et al 1994). Eleven percent of both adherers and nonadherers stated that they used the nebulizer only when they felt they needed to. Forgetting or deciding not to dose has been reported as the most common cause of poor adherence (Figure 3) (Dolce et al 1991). Forgetting is reported by $51 \%$ of the patients, and $31 \%$ of the patients report consciously deciding not to dose.

\section{Demographics}

An evaluation of predictors of patient adherence to longterm home nebulizer therapy in 985 patients with moderate to severe COPD enrolled in the Intermittent Positive Pressure Breathing (IPPB) Trial revealed that $49.4 \%$ of patients were nonadherent (Turner et al 1995). Good adherence was predicted by white race, married status, abstinence from cigarettes and alcohol, serum theophylline level $>9 \mathrm{pg} / \mathrm{mL}$, more severe dyspnea, and reduced $\mathrm{FEV}_{1}(\mathrm{p}<0.05)$. Subjects who were adherent to nebulizer therapy were older, better educated, had a stable lifestyle, were more likely to report that the therapy made them feel better, and were more likely to keep clinic appointments.

Refill adherence tends to be lower in younger patients, but lower in men than women (ratio of repeat prescriptions;
40/60 men/women) (Rovelli et al 1989; Rand et al 1995; Leventhal and Crouch 1997). Men seem to have higher oversupplies (25\%) than women (21\%) and women slightly more undersupplies (22\%) than men (20\%) (Andersson et al 2005). Older patients typically have more difficulty with the correct use of the inhaler than younger patients but there seems to be no difference in errors between men and women (van Beerendonk et al 1998).

A study on adherence to prescribed regimens of 74 patients with COPD reported that almost $54 \%$ of the patients $($ men $=27$, women $=15)$ stopped their medications periodically over the previous 3 months, $47 \%$ (men $=26$, women $=11)$ noted forgetting doses over the previous 3 months, and $44 \%($ men $=23$, women $=11)$ acknowledged being "careless" in taking their medications (Dolce et al 1991). Thirty-nine patients $($ men $=25$, women $=14)$ reported using more medication than was prescribed in times of distress. Thirty-eight percent of the men and $12 \%$ of the women used their inhaled medications with unsatisfactory technique.

Independent variables that are significantly associated with correct user of pMDI included sex and smoking status (Luk et al 2006). Men were more likely to use pMDI correctly: $77 \%$ of men used pMDI correctly, but only $33 \%$ of women used pMDI correctly. Non-smokers were more likely to have correct inhaler technique, whereas smokers were less likely. No significant association was observed between

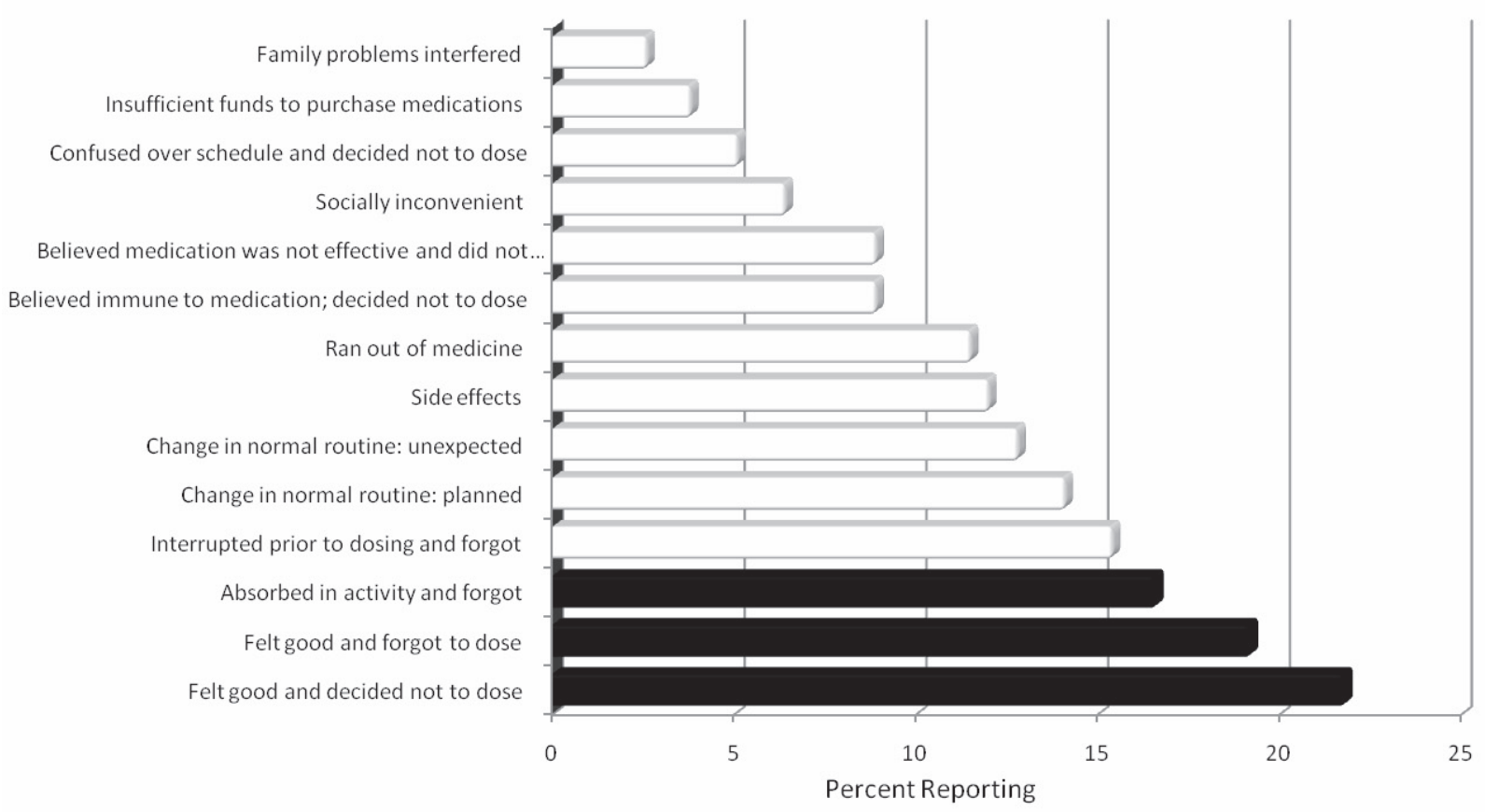

Figure 3 Common causes of poor adherence. (Data from Dolce et al 1991). Solid bars indicate the top three reasons cited for missing medications. 
age, drinking, education level or living condition and correct pMDI technique.

\section{Impact of teaching}

Although patients may read the instruction leaflet and receive face-to-face instruction, it is critical to evaluate whether or not patients are able to use the aerosol delivery device correctly. Patients' interest in reading written medical information such as how to use the inhaler may be influenced by several patient factors including disease state, health locus of control, coping style, health literacy levels, and occupation (Koo et al 2006). Since non-adherent patients have a tendency to report more confusion about medications than the highly adherent group, health care providers may need to spend more time especially with the elderly and those patients with polypharmacy (George et al 2005).

Even immediately after face-to-face instruction patients make mistakes. In a study comparing the Diskus and the Turbuhaler DPIs, $8 \%$ of patients made mistakes using the Diskus DPI and 26\% using the Turbuhaler DPI right after reading the instruction leaflets (van der Palen et al 1998). Retention of instructions on appropriate use of the devices is progressively lost over time (van der Palen et al 1997). Inhalation technique was evaluated on average 6 months after they had received 3 different forms of instruction. Ninety-seven percent of the patients with small-group instruction demonstrated a good inhalation technique in comparison to $75 \%$ after video instruction, and $76 \%$ after personal instruction.

Using "ideal" technique as an outcome, the relative risk of all steps correct in teaching intervention groups compared with non-intervention groups has been around 2.08 (95\% CI 1.59-2.78). The evidence shows that there is no difference between the pMDI and DPI. Any initial difference between the pMDI and DPI appears to be related partly to selection bias since appropriate inhaler technique achieved after a period of teaching has shown equivalent results for both pMDI and DPI (Brocklebank and Ram 2001). The inhaler technique improves by counseling and the percentage of subjects performing steps correctly may double (Luk et al 2006).

Evaluation of the proportion of patients with COPD who are compliant with ICS use after education in a 1-year follow up showed no significant difference when compared with those who did not get the education (Gallefos et al 1999). However, the educated patients with COPD received less than half the amount of SABAs as rescue medications compared with the control group.

A sizeable number of primary care physicians treating patients with COPD are not aware of the GOLD guidelines and seem unclear about the role of inhaled medications at different stages of COPD (Foster et al 2007). Since primary care physicians provide care for a large percentage of patients with mild-to-moderate COPD, their diagnostic skills along with the knowledge and implementation of the guidelines is critical to the education, clinical outcome, and adherence to therapy of their patients with COPD.

\section{Summary}

By considering only adherence to medications and the impact of teaching, we are falling short of recognizing the critical role played by other forms of nonpharmacologic treatment such as smoking cessation, alternative medicine, diet, exercise, and psychotherapy and their impact at different stages of COPD and/or in patients of different cultures. All aspects of therapy and the impact each one has on the currently reported poor adherence to COPD therapy need to be evaluated. Adherence to therapy at different stages of COPD is important since the extent of impairment influences perceived symptoms, medication algorithms, ability to adhere with therapy and perceived benefit of medication. This distinction could have significant implications in important outcomes discussed earlier. However, we could not find reports that measured the impact of specific stages of COPD on adherence to medication.

Therapies for COPD can be effective and improve outcomes only if well prescribed and if they are used by patients. The most common type of nonadherence to therapy is underuse. More than half of patients with COPD report missing or skipping doses of their medication (George et al 2005; Haupt et al 2008; Krigsman et al 2007a, b, c). Forgetting to dose is the most common situational factor that explains poor adherence (Dolce et al 1991; Bosley et al 1994). The decision not to dose due to feeling good is concerning. During respiratory distress, patients often report using more than the prescribed amount of medications (Bosley et al 1994; Dolce et al 1991).

Adherence also depends on clinical efficacy of the prescribed medications. In patients with COPD, a LABA - ICS combination produces a statistically significant and clinically relevant benefit without substantial differences between aerosol delivery systems. The superiority of combination inhalers should be viewed against the increased risk of side effects, particularly pneumonia (Calverley et al 2007). The class of medication appears to be uniformly associated with adherence. There is a noticeable pattern for patients to report better adherence with corticosteroids and antibiotics than with theophylline, inhaled beta agonists, and inhaled 
anticholinergic agents. Unfortunately, the underlying causes of these differences have not been determined. The complexity of medication regimens frequently prescribed for patients with COPD adversely affect adherence to treatment (Krigsman et al 2007a).

When selecting an aerosol delivery device for patients with COPD, the following aspects should be considered to improve adherence to therapy: device - medication availability; clinical setting; patient age and the ability to use the selected device correctly; device use with multiple medications; cost and reimbursement; medication administration time; convenience in both outpatient and inpatient settings; and physician and patient preference. Almost all popular inhalers seem to be acceptable when overall preference is assessed, but most patients choose their devices based on ease of use in general and during an exacerbation, the feel of the device in the hand, ease of opening the cap, and the ability to take the medication quickly in case of an impending exacerbation (van der Palen et al 2007). Patients using combined SVN therapy morning and night with midday inhaler use seem to have the most statistically significant improvements in quality of life. This concomitant regimen may provide the additional symptom relief offered by a SVN with the convenience of an inhaler when patients are away from home (Balzano et al 2000; Tashkin et al 2007). Since most patients consider the pMDI to be more acceptable and the SVN to be more effective, these preferences should be taken into consideration when prescribing a maintenance aerosol inhalation treatment.

There is significant evidence showing that nearly $100 \%$ of patients with COPD make errors on the steps necessary to adequately use inhalers and many patients with COPD display a technique that possibly delivers an inadequate dose of medication (Hesselink et al 2001; Rau 2005; Luk et al 2006). However, the number of instructions needed to obtain a perfect inhalation technique and the type of instruction that sustains patient's mastery over time has not been clearly defined. Regular instructions, supervision, and check up of inhalation technique are the responsibility of the treating physician. Under real-life conditions, inappropriate use of inhalers is common and strongly correlates with a lack of instruction by the caregiver (Sestini et al 2007). The benefit of providing mere information and well-written instructions without "hands-on" demonstration has been thought as not providing information at all (Sestini et al 2007). Health professionals need to assess the utility of written medical information in the tailoring of patient education to meet patient needs.
Although insufficient funds have been reported of limited importance as a factor limiting adherence to a medication regimen (Dolce et al 1991), pharmacoeconomics is considered a relevant issue in clinical practice (Roberts 2006). If reimbursement is considered, SVNs may be more cost effective and may explain why an increasing number of patients request a change to SVN (Rau 2005). Cost of the aerosol delivery device is at least as important as or perhaps more important than cost of the medication for adherence to therapy.

Patients' acceptance and knowledge of the disease process as well as the recommended treatment, faith in the treatment, effective patient - clinician interaction are all critical for optimal medication adherence in patients with COPD. Psychological factors such as depression in patients with COPD have not been extensively studied. Depression may cause a patient to neglect themselves and their treatment and influence respiratory symptoms by being a cause of nonadherence. It is very possible that the increased sense of impairment in quality of life is associated with poor adherence to treatment (DiMatteo et al 2000, 2007). Although some studies have revealed an association between demographic variables such as gender, age, and race to adherence, studies with larger samples are needed (Andersson et al 2005; Luk et al 2006).

There is a need for further research to determine how, when, and where in the course of COPD patients need to be educated on all aspects of their disease to improve adherence to their prescribed therapeutic regimen. Physicians' role on adherence should be thoroughly investigated to establish strategies that improve adherence since current evidence has been focused mostly on the patient level. The impact of poor implementation of existing guidelines for COPD by physicians on patients' adherence to treatment has been poorly investigated. Only about $45 \%$ of primary care physicians taking care of patients with COPD are aware of major COPD guidelines. However $75 \%$ of them do not use them to prescribe therapy for their patients with COPD (Foster et al 2007). The optimal use of recent advances in medicine depends heavily on developing effective communication between health care professionals and their patients (Mellins et al 1992). Strong education initiatives enable patients to respond effectively to the prescribed therapeutic regimens. A collaborative self-management approach recognizes the patient's role in making his or her own health decisions and the physician's role as an educator and facilitator of the patient's health decisions (Barry 2003). Health care practitioners should recognize the complexity of prescribed 
treatments and routinely utilize strategies to promote patient adherence.

Improving efforts by the physicians to increase education about the illness and the treatment options along with the inclusion of psychological treatments in management plans is critical to improving adherence to therapy in patients with COPD who find every day a challenge to adhere to their therapeutic regimen.

\section{Disclosures}

None of the authors has any conflicts of interest to disclose.

\section{References}

Aaron SD, Vandemheen KL, Fergusson D, et al; Canadian Thoracic Society/ Canadian Respiratory Clinical Research Consortium. 2007. Tiotropium in Combination with Placebo, Salmeterol, or Fluticasone - Salmeterol for Treatment of Chronic Obstructive Pulmonary Disease. Ann Intern Med, 146:545-55.

Andersson K, Melander A, Svensson C, et al. 2005. Repeat prescriptions: refill adherence in relation to patient and prescriber characteristics, reimbursement level and type of medication. Eur J Public Health, 15:621-6.

Appleton S, Poole P, Smith B, et al. 2006. Long-acting beta2-agonists for poorly reversible chronic obstructive pulmonary disease. Cochrane Database Syst Rev, 19:3:CD001104.

Balzano G, Battiloro R, Biraghi M, et al. 2000. Effectiveness and acceptability of a domiciliary multidrug inhalation treatment in elderly patients with chronic airflow obstruction: metered dose inhaler versus jet nebulizer. $J$ Aerosol Med, 13:25-33.

Barry MJ. 2003. Chronic obstructive pulmonary disease: developing comprehensive management. Respir Care, 48:1225-34.

Barta S, Crawford A, Roberts C. 2002. Survey of patients' views of domiciliary nebulizer treatment for chronic lung disease. Respir Med, 96:375-81.

Bosley CM, Corden ZM, Rees PJ, et al. 1996. Psychological factors associated with use of home nebulized therapy for COPD. Eur Respir J, 9:2346-50.

Bosley CM, Parry DT, Cochrane GM. 1994. Patient compliance with inhaled medication. Does combining beta agonists with corticosteroids improve compliance? Eur Respir J, 7: 504-9.

Bowton DL, Goldsmith WM, Haponik EF. 1992. Substitution of metereddose inhalers for hand-held nebulizers. Success and cost savings in a large, acute-care hospital. Chest, 101:305-8.

Brocklebank D, Ram F. 2001. Comparison of the effectiveness of inhaler devices in asthma and chronic obstructive airways disease: a systematic review of the literature. Health Technology Assessment, $5: 1-155$.

Brown PH, Lenney L, Armstrong S, et al. 1992. Breath-actuated inhalers in chronic asthma: comparison of Diskhaler and Turbuhaler for delivery of beta-agonists. Eur Respir J, 5:1143-45.

Calverley PM, Anderson JA, Celli B, et al; TORCH investigators. 2007. Salmeterol and fluticasone propionate and survival in chronic obstructive pulmonary disease. $N$ Engl J Med, 356:775-89.

Calverley PM, Bonsawat W, Cseke Z, et al. 2003. Maintenance therapy with budesonide and formoterol in chronic obstructive pulmonary disease. Eur Respir J, 22:912-9.

Calverley P, Pauwels DR, Löfdahl CG, et al. 2005. Relationship between respiratory symptoms and medical treatment in exacerbations of COPD. Eur Respir J, 26:406-13.

Calverley P, Pauwels R, Vestbo J, et al. 2003. Combined salmeterol and fluticasone in the treatment of chronic obstructive pulmonary disease: a randomized controlled trial. Lancet, 361:449-56.
Food and Drug Administration. 2007. Center for Drug Evaluation and Research.drugs@FDA. Rockville, MD. URL: http://www.accessdata. fda.gov/scripts/cder/drugsatfda/. Accessed April 22, 2008.

Chapman KR, Arvidsson P, Chuchalin AG, et al. 2002. The addition of salmeterol 50 microg bid to anticholinergic treatment in patients with COPD: a randomized, placebo controlled trial. Can Respir J, 9:178-85.

Chrischilles E, Gilden D, Kubisiak J, et al. 2002. Delivery of ipratropium and albuterol combination therapy for chronic obstructive pulmonary disease: effectiveness of a two-in-one inhaler versus separate inhalers. Am J Manag Care, 8:902-11.

Chronic Obstructive Pulmonary Disease (COPD). Fact sheet No 315. November 2007 [online]. Accessed February 26, 2008. URL: http:// www.who.int/mediacentre/factsheets/fs315/en/index.html.

Chryssidis E, Frewin DB, Frith PA, et al. 1981. Compliance with aerosol therapy in COPD. NZ Med J, 250:375-77.

Cochrane GM. 1992. Therapeutic compliance in asthma: its magnitude and implications. Eur Respir J, 5:122-24.

Crompton GK. 1990. The adult patient's difficulties with inhalers. Lung, 168(Suppl):658-62.

D’Urzo AD, De Salvo MC, Ramirez-Rivera A, et al. 2001. In patients with COPD, treatment with a combination of formoterol and ipratropium is more effective than a combination of salbutamol and ipratropium: a 3-week, randomized, double-blind, within-patient, multicenter study. Chest, 119:1347-56.

Dal NR, Eandi M, Pradelli L, et al. 2007. Cost-effectiveness and healthcare budget impact in Italy of inhaled corticosteroids and bronchodilators for severe and very severe COPD patients. Int J Chron Obstruct Pulmon Dis, 2:169-76.

Dames P, Gleich B, Flemmer A, et al. 2007. Targeted delivery of magnetic aerosol droplets to the lung. Nature Nanotechnol, 2:495-99.

Dhand R. 2008. Aerosol delivery during mechanical ventilation: from basic techniques to new devices. J Aerosol Med, 21:45-60.

DiMatteo MR, Haskard KB, Williams SL. 2007. Health beliefs, disease severity, and patient adherence: a meta-analysis. Med Care, 45:521-8.

DiMatteo MR, Lepper HS, Croghan TW. 2000. Depression is a risk factor for noncompliance with medical treatment: meta-analysis of the effects of anxiety and depression on patient adherence. Arch Intern Med, 160:2101-7.

Dolce JJ, Crisp C, Manzella B, et al.1991. Medication Adherence Patterns in Chronic Obstructive Pulmonary Disease. Chest, 99:837-41.

Dolovich MB, Ahrens RC, Hess DR, et al. 2005. Device selection and outcomes of aerosol therapy: evidence-based guidelines. Chest, 127:335-71.

Dompeling E, Van Grunsven PE, Van Schayck CP, et al. 1992. Treatment with inhaled steroids in asthma and chronic bronchitis: longterm compliance and inhaler technique. Fam Pract, 9:161-66.

Farmer KC. 1999. Methods for measuring and monitoring medication regimen adherence in clinical trials and clinical practice. Clin Ther, 21:1074-90.

Gallefoss F, Bakke PS. 1999. How does patient education and self-management among asthmatics and patients with chronic obstructive pulmonary disease affect medication? Am J Respir Crit Care Med, 160:2000-5.

George J, Kong DC, Thoman R, et al. 2005. Factors associated with medication nonadherence in patients with COPD. Chest, 128:3198-204.

Global Initiative for Chronic Obstructive Lung Disease Global strategy for the diagnosis, management, and prevention of COPD. Updated 2007 [online]. Accessed February 26, 2008. URL: http://www.goldcopd. com/Guidelineitem. asp?11 =2\&12=1\&intId=989.

Gross N, Tashkin D, Miller R, et al. 1998. Inhalation by nebulization of albuterol-ipratropium combination (Dey combination) is superior to either agent alone in the treatment of chronic obstructive pulmonary disease. Respiration, 65:354-62.

Hanania NA, Darken P, Horstman D, et al. 2003. The efficacy and safety of fluticasone propionate (250 microg)/salmeterol (50 microg) combined in the diskus inhaler for the treatment of COPD. Chest, 124:834-43.

Hanlon JT, Schmader KE, Ruby CM, et al. 2001. Suboptimal prescribing in elderly inpatients and outpatients. J Am Geriatr Soc, 49:200-9. 
Harrow BS, Strom BL, Gans JA. 1997. Impact of pharmaceutical underutilization: a study of insurance drug claims data. J Am Pharm Assoc (Wash), NS37:511-6.

Haupt D, Krigsman K, Nilsson JL. 2008. Medication persistence among patients with asthma/COPD drugs. Pharm World Sci, 5 Feb [Epub ahead of print].

Hajjar E, Hanlon JT, Sloane RJ, et al. 2005. Unnecessary drug use in frail older people at hospital discharge. J Am Geriatr Soc, 53:1518-23.

Haycox A, Bagust A. 1999. Clinical guidelines: the hidden costs. BMJ, 318:391-3.

Haynes RB, Taylor DW, Sackett DL. 1979. Compliance in healthcare. Baltimore, MD: Johns Hopkins University Press. p 1-7.

Hesselink AE, Penninx BW, Wijnhoven HA, et al. 2001. Determinants of an incorrect inhalation technique in patients with asthma or COPD Scand J Prim Health Care, 19:255-60.

Incalzi RA, Pedoen C, Onder G, et al. 2001. Predicting length of stay of older patients with exacerbated chronic obstructive pulmonary disease. Aging, 13:49-57.

Insel KC, Reminger SL, Hsiao CP. 2006. The negative association of independent personality and medication adherence. J Aging Health, 18:407-418.

James PNE, Anderson JB, Prior JG, et al. 1985. Patterns of drug taking in patients with chronic airflow obstruction. Postgrad Med J, 61:7-10.

Jones RCM, Hyland ME, Hanney K, et al. 2004. A qualitative study of compliance with medication and lifestyle modification in Chronic Obstructive Pulmonary Disease (COPD). Primary Care Respir J, 13:149-54.

Kaplan RM, Ries AL. 2005. Quality of life as an outcome measure in pulmonary diseases. J Cardiopulm Rehabil, 25:321-31.

Kaplan RM, Toshima MT, Atkins CJ, et al. 1990. Behavioral interventions for patients with COPD. In O'Keene JK, Shumaker SA (eds). Adoption and Maintenance of Behavior for Optimal Health. New York: Springer.Verlag.

Koo M, Krass I, Aslani P. 2006. Enhancing patient education about medicines: Factors influencing reading and seeking of written medicine information. Health Expect, 9:174-87.

Krigsman K, Lars JG, Ring L. 2007c. Refill adherence for patients with asthma and COPD: comparison of a pharmacy record database with manually collected repeat prescriptions. Pharmacoepidemiol Drug Saf, 16:441-8.

Krigsman K, Moen J, Nilsson JL, et al. 2007a. Refill adherence by the elderly for asthma/chronic obstructive pulmonary disease drugs dispensed over a 10-year period. J Clin Pharm Ther, 32:603-11.

Krigsman K, Nilsson JL, Ring L. 2007b. Adherence to multiple drug therapies: refill adherence to concomitant use of diabetes and asthma/COPD medication. Pharmacoepidemiol Drug Saf, 16:1120-8.

Lee KH, Phua J, Lim TK. 2006. Evaluating the pharmacoeconomic effect of adding tiotropium bromide to the management of chronic obstructive pulmonary disease patients in Singapore. Respir Med, 100:2190-6.

Leventhal EA, Crouch M. 1997. Are there differentials in perceptions of illness across the life-span? In Petrie KJ, Weinman J (ed). Perceptions of health and illness. Amsterdam: Harwood Academic Publishers. $\mathrm{p} 77-102$.

Ley P, Bradshaw PW, Eaves L, et al. 1973. A method for increasing patients' recall of information presented by doctors. Psychol Med, 3:217-20.

Lipton HL, Bero LA, Bird JA, et al. 1992. Undermedication among geriatric outpatients: Results of a randomized controlled trial. Ann Rev Gerontol Get, 12:95-108.

Lucas A, Smeenk F, Smeele I, et al. 2008. Overtreatment with inhaled corticosteroids and diagnostic problems in primary care patients, an exploratory study. Fam Pract, [Epub ahead of print].

Luk H, Chan P, Lam F, et al. 2006. Teaching chronic obstructive airway disease patients using a metered-dose inhaler. Chin Med J, 119:1669-72.

Mahler DA, Wire P, Horstman D, et al. 2002. Effectiveness of fluticasone propionate and salmeterol combination delivered via the Diskus device in the treatment of chronic obstructive pulmonary disease. Am J Respir Crit Care Med, 166:1084-91.
Maio V, Pizzi L, Roumm Ar, et al. 2005. Pharmacy utilization and the Medicare Modernization Act. Milbank Q, 83:101-30.

McFadden ER. 1986. Inhaled aerosol bronchodilators. Baltimore: Williams and Wilkins.

Mellins RB, Evans D, Zimmerman B, et al. 1992. Patient compliance. Are we wasting our time and don't know it? Am Rev Respir Dis, 146:1376-77.

Moore AC, Stone S. 2004. Meeting the needs of patients with COPD: patients' preference for the Diskus inhaler compared with the Handihaler. Int J Clin Pract, 58:444-50.

Moriskey D, Green L, Levine D. 1986. Concurrent and predictive validity of a self reported measure of medication adherence. Med Care, 24:67-74.

Nannini L, Cates CJ, Lasserson TJ, et al. 2007a. Combined corticosteroid and long-acting beta-agonist in one inhaler versus placebo for chronic obstructive pulmonary disease. Cochrane Database Syst Rev, 4: CD003794.

Nannini L, Cates CJ, Lasserson TJ, et al. 2007b. Combined corticosteroid and long-acting beta-agonist in one inhaler versus long-acting betaagonists for chronic obstructive pulmonary disease. Cochrane Database Syst Rev, 4:CD006829.

Nannini L,Cates CJ, Lasserson TJ, et al. 2007c. Combined corticosteroid and long-acting beta-agonist in one inhaler versus inhaled steroids for chronic obstructive pulmonary disease. Cochrane Database Syst Rev, 4:CD006826.

Nilsson JLG, Johansson H, Wennberg M. 1995. Large differences between prescribed and dispensed medicines could indicate undertreatment. Drug Inf J, 29:1243-6.

Oba Y. 2007. Cost-effectiveness of long-acting bronchodilators for chronic obstructive pulmonary disease. Mayo Clin Proc, 82:575-82.

Onukwugha E, Mullins CD, Delisle S. 2008. Using cost-effectiveness analysis to sharpen formulary decision-making: the example of tiotropium at the Veterans Affairs Health Care System. Value Health, [Epub ahead of print].

Peters J, Stevenson M, Beverley C, et al. 2002. The clinical effectiveness and cost effectiveness of inhaler devices used in the routine management of chronic asthma in older children: a systematic review and economic evaluation. Health Technol Assess, 6:5.

Ramsey SD. 2000. Suboptimal medical therapy in COPD. Chest, 117:33S-7S

Rand CS, Nides M, Cowles MK, et al; for the Lung Health Study Research Group. 1995. Long-term metered-dose inhaler adherence in a clinical trial. Am J Respir Crit Care Med, 152:580-88.

Rashid A. 1982. Do patients cash prescriptions? BMJ, 284:24-6.

Rau JL. 2005. The inhalation of drugs: advantages and problems. Respir Care, 50:367-82.

Roberts M. 2006. Racial and ethnic differences in health insurance coverage and unusual source of health care, 2002. Rockville, MD: Agency for Healthcare Research and Quality. MEPS Chartbook 14. AHRQ Pub no 06-0004.

Rodriguez-Roisin R. 2005. The airway pathophysiology of COPD: implications for treatment. Int J Chron Obstruct Pulmon Dis, 2:253-62.

Rovelli M, Palmeri D, Vossler E, et al. 1989. Noncompliance in organ transplant recipients. Transplant Proc, 21:833-4.

Rutten-van Mölken MP, Oostenbrink JB, Miravitlles M, et al. 2007. Modelling the 5-year cost effectiveness of tiotropium, salmeterol and ipratropium for the treatment of chronic obstructive pulmonary disease in Spain. Eur J Health Econ, 8:123-35.

Serra-Batlles J, Plaza V, Badiola C, et al. 2002. Patient perception and acceptability of multidose dry powder inhalers: a randomized crossover comparison of Diskus/Accuhaler with Turbuhaler. J Aerosol Med, 15:59-64.

Sichletidis L, Kottakis J, Marcou S, et al. 1999. Bronchodilatory responses to formoterol, ipratropium, and their combination in patients with stable COPD. Int J Clin Pract, 53:185-88.

Sin DD, McAlister FA, Man SF, et al. 2003. Contemporary management of chronic obstructive pulmonary disease: scientific review. JAMA, 290:2301-12. 
Sirey JA, Raue PJ, Alexopoulos GS. 2007. An intervention to improve depression care in older adults with COPD. Int J Geriatr Psychiatry, 22:154-9.

Smyth HD. 2005. Propellant-driven metered-dose inhalers for pulmonary drug delivery. Expert Opin Drug Deliv, 2(1):53-74.

Snider GL. 1985. Distinguishing among asthma, chronic bronchitis, and emphysema. Chest, 87(Suppl 1):35S-39S.

Steinman MA, Landefeld CS, Rosenthal GE, et al. 2006. Polypharmacy and prescribing quality in older people. J Am Geriatr Soc, 54:1516-23.

Stuart B. 2004. Navigating the new Medicare drug benefit. Am J Geriatr Pharmacother, 2:75-80.

Strauss AL, Glaser BG. 1975. Chronic illness and the quality of life St. Louis: Mosby.

Szafranski W, Cukier A, Ramirez A, et al. 2003. Efficacy and safety of budesonide/formoterol in the management of chronic obstructive pulmonary disease. Eur Respir J, 21:74-81.

Tashkin DP, Klein GL, Colman SS, et al. 2007. Comparing COPD treatment: nebulizer, metered dose inhaler, and concomitant therapy. Am J Med, 120:435-41.

Taylor DR. Kinney CD, McDevitt DC. 1984. Patient compliance with oral theophylline therapy. Br J Clin Pharm, 17:15-20.

Thompson J, Irvine T, Grathwohl K, et al. 1994. Misuse of metered-dose inhalers in hospitalized patients. Chest, 105:715-17.

Turner J, Wright E, Mendella L, et al. 1995. Predictors of patient adherence to long-term home nebulizer therapy for COPD. The IPPB Study Group. Intermittent Positive Pressure Breathing. Chest, 108:394-400.

Van Beerendonk I, Mesters I, Mudde AN, et al. 1998. Assessment of the inhalation technique in outpatients with asthma or chronic obstructive pulmonary disease using a metered-dose inhaler or dry powder device. J Asthma, 35:273-79. van der Palen J, Eijsvogel M, Kuipers BF, et al. 2007. Comparison of the Diskus $^{\circledR}$ Inhaler and the Handihaler ${ }^{\circledR}$ Regarding Preference and Ease of Use. J Aer Med, 20:38-44.

van der Palen J, Klein JJ, Kerkhoff AHM. 1994. Poor technique in the use of inhalation drugs by patients with chronic bronchitis/pulmonary emphysema. Ned Tijdschr Geneeskd, 138:1417-22.

van der Palen J, Klein JJ, Kerkhoff AHM, et al. 1995. Evaluation of the effectiveness of four different inhalers in patients with chronic obstructive pulmonary disease. Thorax, 50:1183-87.

van der Palen J, Klein JJ, Kerkhoff AH, et al. 1997. Evaluation of the longterm effectiveness of three instruction modes for inhaling medicines. Patient Educ Couns, 32:S87-S95.

van der Palen J, Klein JJ, Schildkamp AM. 1998. Comparison of a new multidose powder inhaler (Diskus/Accuhaler) and the Turbuhaler regarding preference and ease of use. J Asthma, 35:147-52.

Windsor BA, Green LW, Roseman 3M. 1980. Health promotion and maintenance for patients with chronic obstructive pulmonary disease: a review. J Chronic Dis, 33:5-12.

Woodman K, Bremner P, Burgess C, et al. 1993. A comparative study of the efficacy of beclomethasone dipropionate delivered from a breath activated and conventional metered dose inhaler in asthmatic patients. Curr Med Res Opin, 13:61-9.

World Health Organization. 2003. Adherence to long-term therapies. Evidence for action. Geneva: World Health Organization.

World Health Organization. Chronic Respiratory Diseases [online]. Accessed February 26, 2008. URL: http:/www.who.int/gard/publications/chronic_respiratory_diseases.pdf.

Yang IA, Fong KM, Sim EH, et al. 2007. Inhaled corticosteroids for stable chronic obstructive pulmonary disease. Cochrane Database Syst Rev, 2:CD002991. 